\title{
PENGALOKASIAN ANGGARAN DALAM PEMBANGUNAN INFRASTRUKTUR DI KABUPATEN JEMBRANA
}

\author{
IGA Tiara Sinta Maharani, Angga Kusumardana, Imanuel Kinkin Sumbogo, Ni \\ Made Nuadi Yasinta, Made Rani Mas Erlin S., Andika Surya Pratama \\ Jurusan Akuntansi, Universitas Pendidikan Ganesha, Singaraja, Bali, Indonesia
}

\begin{abstract}
Abstrak
Penelitian ini bertujuan untuk menjabarkan bagaimana perkembangan pembangunan infrastruktur di Kabupaten Jembrana, apa saja tindakan yang perlu diambil pemerintah dalam pembangunan infrastruktur di Kabupaten Jembrana, aagaimana pertimbangan prioritas pembangunan infrastruktur di Kabupaten Jembrana, serta bagaimana penyaluran anggaran dalam pembangunan infrastruktur Kabupaten Jembrana. Pengumpulan data dilakukan melalui teknik penelusuran dokumen. Hasil penelitian menunjukkan bahwa perkembangan pembangunan infrastruktur di kabupaten Jembrana semakin meningkat dengan melihat dari pembangunan transportasinya. Selain itu, rencana strategik yang memuat rencana dalam kurun waktu lima tahun telah disusun sesuai dengan tahapannya, faktor-faktor penghambat dan faktor-faktor pendorong dan juga memperhitungkan tantangan dan peluang untuk pengembangan dan peningkatan mutu pelayanan.
\end{abstract}

Kata kunci: alokasi anggaran; pembangunan infrastruktur, kabupaten jembrana

Abstract
This study aims to describe how the development of infrastructure development in Jembrana Regency, what actions the government needs to take in infrastructure development in Jembrana Regency, how to consider the priority of infrastructure development in Jembrana Regency, and how the budget distribution in Jembrana Regency infrastructure development. Data collection is done through document search techniques. The results showed that the development of infrastructure development in Jembrana district had increased with regard to the development of transportation. In addition, the strategic plan that contains the plan within a period of five years has been prepared in accordance with the stages, inhibiting factors and driving factors and also taking into account the challenges and opportunities for the development and improvement of service quality.

Keywords: budget allocation; infrastructure development, jembrana district

\section{Pendahuluan}

Infrastruktur merupakan seluruh fasilitas baik fisik maupun non fisik yang sengaja dibangun oleh pemerintah atau perorangan untuk mendukung terlaksananya kegiatan masyarakat. Pembangunan infrastruktur merupakan hal yang penting yang pengadaannya harus disegerakan karena berhubungan dengan kebutuhan dasar masyarakat sehari-hari dalam lingkup sosial dan ekonomi. Infrastruktur publik merupakan tanggung jawab pemerintah sebagai bentuk tanggung jawab dan kompensasi dari pembayaran pajak oleh warga negara. Infrastruktur publik sangat penting artinya karena sangat mempengaruhi kelancaran aktivitas sosial dan ekonomi masyarakat. Dalam hal ini Kabupaten Jembrana merupakan akses utama yang menghubungkan jalur transportasi darat dari Pulau Jawa sampai dengan Denpasar yang merupakan ibu kota dari Pulau Bali.

Pembangunan infrastruktur merupakan salah satu aspek penting dan vital untuk meningkatkan daya saing daerah untuk mencapai tingkat kesejahteraan yang tinggi dan berkelanjutan sehingga mempercepat proses pembangunan nasional maupun daerah. Infrastruktur juga memegang peranan penting sebagai salah satu roda penggerak pertumbuhan ekonomi. Ini mengingat gerak laju dan pertumbuhan ekonomi tidak dapat dipisahkan dari ketersediaan infrastruktur seperti transportasi, telekomunikasi, tenaga listrik, penyediaan air, pembuangan limbah, dan pelayanan-pelayanan lainnya yang serupa. Mengenai aturan tentang kewajiban membangun infrastruktur daerah Kabupaten Jembrana diatur dalam Peraturan Daerah Kabupaten Jembrana Nomor 6 Tahun 2016 tentang Rencana 
Pembangunan Jangka Menengah Daerah Semesta Berencana Kabupaten Jembrana Tahun 2016-2021.

Pelaksanaan pembangunan infrastruktur yang dilaksanakan di daerah tentu harus mendapat perhatian serius, karena faktor terbesar yang dihadapai pembangunan selama ini adalah buruknya kualitas pembangunan infrastruktur khususnya di daerah Kabupaten Jembrana. Kondisi jalur utama transportasi darat yang di Kabupaten Jembrana memerlukan penataan khusus karena kondisinya yang kurang baik dan melihat jalur tersebut merupakan jalur nasional Denpasar-Gilimanuk.

Perhatian khusus yang perlu diberikan pada jalur nasional Denpasar-Gilimanuk seharusnya ditujukan pada penyaluran anggaran untuk perbaikan infrastruktur seperti jalan utama yang menghubungkan Denpasar-Gilimanuk yang kualitasnya bisa dikatakan kurang baik. Kemudian kondisi jembatan pada jalan utama tersebut kurang baik sehingga jembatan tersebut tidak dapat dioperasikan secara maksimal, saat ini kondisi jembatan itu dalam tahap perbaikan. Selain kondisi infrastruktur transportasi yang kurang baik, infrastruktur seperti tenaga listrik kurang dioptimalkan dengan baik, dalam hal ini juga dapat dilihat dari pencahayaan pada jalan utama.

Adapun permasalahan yang dapat dirumuskan yaitu bagaimana perkembangan pembangunan infrastruktur di Kabupaten Jembrana, apa saja tindakan yang perlu diambil pemerintah dalam pembangunan infrastruktur di Kabupaten Jembrana, aagaimana pertimbangan prioritas pembangunan infrastruktur di Kabupaten Jembrana, serta bagaimana penyaluran anggaran dalam pembangunan infrastruktur Kabupaten Jembrana.

\section{Hasil dan Pembahasan}

\subsection{Perkembangan Pembangunan Infrastruktur di Kabupaten Jembrana}

Penyelenggaraan kegiatan Dinas Pekerjaan Umum yang telah terlaksana merupakan kegiatan pendukung dalam pencapaian Visi dan Misi Dinas Pekerjaan Umum Kabupaten Jembrana. Visi Dinas Pekerjaan Umum Kabupaten Jembrana yaitu : TERWUJUDNYA SARANA PRASARANA SERTA PELAYANAN PEKERJAAN UMUM KABUPATEN JEMBRANA YANG PRIMA, GUNA MENUNJANG KESEJAHTERAAN MASYARAKAT JEMBRANA dan sesuai dengan startegi dan arah kebijakan Kabupaten Jembrana untuk mencapai tujuan pembangunan daerah pada Misi Keempat yaitu dengan Meningkat kuantitas dan kualitas sarana dan prasarana publik dengan memperhatikan kelestarian lingkungan, maka tujuan yang hendak dicapai adalah: Meningkatkan kualitas Pekerjaan Umum, Meningkatkan pengelolaan perumahan, meningkatkan penyelenggaraan penataan ruang dan perumahan, menurunkan eksploitasi sumberdaya mineral. Dalam usaha mewujudkan visi Dinas Pekerjaan Umum Kabupaten Jembrana, maka pada tahun 2014 telah menyelenggarakan berbagai kegiatan yang berkaitan dengan tugas pokok dan fungsi Dinar Pekerjaan Umum sebagai salah satu instansi pemerintahan daerah Kabupaten Jembrana. Realisasi pencapaian target kinerja Dinas Pekerjaan Umum Kabupaten Jembrana. Berdasarkan kebijakan keuangan yang telah ditetapkan dalam Kebijakan Umum APBD Pemerintahan Kabupaten Jembrana Tahun anggaran 2014, ikhtisar realisasi pencapaian target kinerja Dinas Pekerjaan Umum Kabupaten Jembrana adalah mencapai sebesar Rp. 98.136.471.267,00 atau 93,58 \% yang berarti masih lebih kecil lagi sebesar Rp 6.736.019.643,18 atau 6,24 \% dari anggaran belanjayang disediakan sebesar Rp. 104.872.490.910,18 dengan realisasi sebagai berikut:

Realisasi Belanja Langsung adapun rincian realisasi pencapaian target kinerja pada Dinaas Pekerjaan Umum Kabupaten Jembrana guna menunjang kegiatan pelayanan publik (infrastruktur), adalah sebesar Rp. 92.566.487.208,00 (93,55\%), yang berarti masih lebih kecil sebesar Rp.6.381.122.482,18 (6,45\%) dari target yang ditetapkan sebesar Rp. 98.947.609.690,18 hal ini terjadi disamping karena terjadinya efesiensi dimana penawaran kegiatan proyek dibawah pagu anggaran akibat dari terjadinya kompetisi penawaran antar penyedia jasa dalam batas kewajaran dan juga disebabkan oleh ada beberapa kegiatan yang tidak dapat dilaksanakan yaitu untuk kegiatan:

a. Kegiatan Penyusunan Norma Standar dan Manual (NSPM) dengan pagu anggaran Rp. 25.410.000,00 (Dua puluh lima juta empat ratus sepuluh ribu rupiah) tidak terealisasi, 
karena kegiatan ini sudah dianggarkan di Sekretariat Dewan dalam bentuk inisiatip dewan (out come) sudah terlaksana. Kegiatan penyediaan sarana air bersih dan sanitasi dasar terutama bagi masyarakat miskin yang nilainya Rp.3.744.233.000,00 ( tiga milyar tujuh ratus empat puluh empat juta dua ratus tiga puluh tiga ribu rupiah), realisasi anggarannya rendah karena anggaran terserap hanya untuk honor/gaji TFL (Tenaga Fasiliator Lapangan) namun fisik/kontruksi belum bisa terlaksana seperti tahun lalu, disebabkan terkendala kesiapan lahan.

Perkembangan pembangunan infrastruktur di kabupaten Jembrana dapat dilihat dari berbagai bidang, yang salah satunya adalah bidang bina marga. Bidang bina marga dipipin oleh seorang Kepala Bidang yang Mempunyai tugas pokok yang antara lainnya yaitu Perencanaan, Pembinaan, Pengawasan, Pengendalian pelaksanaan pekerjaan dan pengawasan pemanfaatan jalan dan jembatan.

a. Jalan menurut statusnya ada tiga jenis jalan di kabupaten Jembrana yaitu jalan Nasional $(71,320 \mathrm{~km})$, jalan Provinsi $(30,870 \mathrm{~km})$ dan jalan Kabupaten $(941,023 \mathrm{~km})$. Panjang jalan di kabupaten Jembrana tahun 2015 yaitu $941,023 \mathrm{~km}$ dngan ruas jalan sebanyak 653 (aspal 915,522 km dan krikil 25,501 km). Menurut kondisinya jalan berkondisi baik sepanjang 456,439 km jalan dengan kondisi sedang sepanjang $135,525 \mathrm{~km}$ jalan dengan kondisi rusak 215,096 km, jalan dengan kondisi rusak berat sepanjang 133,963 km.

b. Jembatan, jembatan nasional dari tahun 2013 tercatat berjumlah 38 jembatan hinggatahun 2015 dengan menggunakan bahan kontruksi beton. Jembatan provinsi dari tahun 2013 sampai tahun 2015 tercatat sejumlah 3 dengan menggunkan bahan kontruksi beton. Jembatan kabupaten dari tahun 2013 sampai dengan 2015 tercatat sejumlah 96 dengan bahan kontruksi beton dan baja.

Dalam melaksanakan tugas pokok bidang sebagaimana dimaksud ayat (1) menyelenggarakan fungsi :

a. Penyusunan rencana kerja Bidang Bina Marga berdasarkan kebijakan dinas

b. Penyelenggaraan, pengawasan terhadap pelaksanaan kegiatan serta pengambilan langkah-langkah dalam penanggulangan jalan dan jembatan beserta fasilitasnya

c. Pengevaluasian pelaksanaan tugas inventarisasi permasalahan Bidang serta mencari alternative pemecahannya, dan

d. Pelaksanaan tugas lainnya yang diberikan oleh atasan sesuai ugas bidang

Kepala bidang sebagaimana dimaksud ayat (1), dengan rincian tugas sebagai berikut :

a. Menyusun rencana dan program kerja Bidang Bina Marga berdasarkan kebijakan Dinas

b. Menyelanggarakan pengawasan pengendalian dan pelaksanaan kegiatan Bidang

c. Memberikan rekomendasi dan pengawasan pemanfaatan jalan beserta fasilitasnya

d. Menyelenggarakan penanggulangan pemanfaatan jalan beseta fasilitasnya

e. Memberikan bantuan teknis kepada instansi lainnya

f. Memberikan pertimbangan/kajian teknis kepada atasan

g. Mengkoordinasikan Kepala Seksi agar terjalin kerja sama yang baik dan saling mendukung

h. Memberikan petunjuk kepada kepala seksi dan bawahan agar pelaksanaan tugas berjalan sesuai pedoman dan ketentuan yang berlaku

i. Menilai hasil kerja kepala seksi dan bawahan dengan jalan memonitor dan mengavaluasi hasil kerjanya untuk bahan pengembangan karier

j. Melaporkan hasil pelaksanaan tugas/kegiatan kepada atasan dan

k. Melaksanakan tugas dinas lain yang diberikan oleh atasan sesuai dengan tugasnya Dengan 3 Seksi yaitu :

1) Seksi perencanaan dan pembinaan Bina Marga

Seksi Perencanaan dan Pembinaan Bina Marga dipimpin oleh Kepala Seksi yang mempunyai tugas pokok melaksanakan kajian dan pengembangan dalam perencanaan jalan dan jembatan, dan menyelenggarakan fungsi :

a. Penyusunan rencana kegiatan Seksi berdasarkan kebijakan Bidang

b. Pelaksanaan perencanaan infrastruktur bina marga

c. Pembinaan di Bidang Bina Marga

d. Pelaksana tugas dinas lain yang diberikan oleh atasan sesuai dengan tugasnya. 
2) Seksi Pembangunan dan Pengelolaan Bina Marga

Seksi Pembangunan dan Pengelolaan Bina Marga Dipimpin Oleh Kepala Seksi yang mempunyai tugas pokok menyiapkan dokumen/bahan dalam melaksanakan pengembangan dan pengelolaan jalan dan jembatan, dan menyelenggarakan fungsi :

a. Penyusunan rencana kegiatan Seksi sesuai kebijakan Bidang

b. Pelaksanaan penyimpanan dokumen/bahan dalam melaksanakan pengembangan dan pengellaan jembatan dan jembatan

c. Pelaksanaan tugas lain yang diberikan oleh atasan sesuai dengan tugasnya

3) Seksi Pengawasan dan Pengendalian Bina Marga

Seksi Pengawasan dan Pengendalian Bina Marga di Pimpin oleh Kepala Seksi yang mempunyai tugas pokok melaksanakan pengawasan dan pengendalian kegiatan pembangunan serta pengelolaan jalan dan jembatan, dan menyelenggarakan fungsi :

a. Penyusunan rencana kegiatan Seksi sesuai kebijakan Bidang

b. Penyiapan dokumen/bahan dalam melaksanakan pengawasan, pemeliharaan evaluasi dan pengendalian jalan dan jembatan

c. Pelaksanakan tugas lain yang diberikan oleh atasan sesuai bidang tugasnya.

\subsection{Tindakan yang Perlu Diambil Pemerintah Dalam Pembangunan Infrastruktur di Kabupaten Jembrana}

Dalam hal pembangunan infrastruktur di kabupaten Jembrana tindakan pemerintrah dalam hal ini adalah dengan melakukan perencanan kinerja. Perencanaan kinerja Dinas pekerjaan Umum Kabupaten Jembrana merupakan proses penyusunan rencana kinerja sebagai penjabaran dari sasaran dan program yang telah ditetapkan dalam rencana strategik, yang akan dilakasanakan oleh Dinas Pekerjaan Umum melalui berbagai kegiatan tahunan. Di dalam rencana kinerja ditetapkan rencana capaian kinerja tahunan untukn seluruh indikator kinerja yang ada pada tingkat sasaran dan kegiatan. Perencanaan tahunan merupakan proses penetapan kegiatan tahunan dan indikator kinerja berdaarkan program, kebijakan dan sasaran yang telah ditetapkan dalam rencana strategik. Hasil dari proses ini berupa rencana kinerja tahunan. Namun dalam setiap perencanaan maupun pelaksanaan kinerja tetap saja ada kendala ataupun masalah yang dihadapi oleh pemerintah.

Permasalahan yang di hadapi dalam pembangunan infrastruktur di kabupaten Jembarana adalah, dalam hal pembangunan jalan kendala yang dihadapi yaitu anggaran yang ada belum semua ruas jalan dapat direhab, pada saat adanya penambahan anggaran mendapat waktu pengerjaan sangat terbatas, pengerjaan pembangunan infrastruktur jalan juga sangat tergantung pada keadaan cuaca. Kemuadian dalam program kegiatan pembangunan jalan dan jembatan, kegiatan pembangunan jembatan sudah terlaksana dengan baik sesuai dengan porsi anggaran yang ada akan tetapi kendala yang dihadapi dalam menjalankan program kegiatan pembangunan jalan dan jembatan, kegiatan pembangunan jembatan adalah pembebasan tanah pada lokasi jembatan, akses jalan menuju lokasi jembatan kondisinya sulit dilalui.

Permasalahan dalam pembangunan infrastruktur di kabupaten Jembrana sangat di dukung dengan anggaran yang diberikan setiap tahun melalui Dana Alokasi Khusus atau DAK yang mana DAK adalah suatu dana yang bersumberkan dari APBN yang dialokasikan ke daerah untuk mendanai kegiatan khusus yang menjadi urusan daerah dan sesuai dengan skala prioritas nasional. Tujuan pemberian DAK yaitu membantu daerah, untuk mendanai kebutuhan sarana dan prasarana pelayanan dasar masyarakat, serta untuk mendorong percepatan pembangunan daerah sehingga tercapainya sasaran prioritas daerah. Proses penganggaran DAK harus dilengkapi dengan data-data yang akurat agar pagu DAK yang diperoleh daerah sesuai dengan kriteria yang sudah ditentukan oleh peraturan perundangundangan. Proses penyaluran DAK berbeda dengan dana transfer lainnya yang menggunaka triwulan, khusus untuk DAK penyaluran ke Kas Umum Daerah berdasarkan progress yang diserap oleh pemerintah daerah. Hal-hal lain yang harus diperhatikan dalam

pelaksanaan DAK seperti peraturan Mentri Keuangan tentang pelaksanaan dan pertanggungjawaban anggaran transfer ke daerah dan surat edaran tentang langkahlangkah menghadapi akhir tahun, dalam rangka penyaluran anggaran transfer ke daerah. 
Karena aturan-aturan tersebut mengatur batas waktu DAK, sehingga apabila pemerintah daerah tidak tepat menyampaikan laporan atau penyerapan dibawah ketentuan maka sisa DAK tidak akan disalurka ke Kas Umum Daerah ( hangus ) dan juga daerah harus menanggung pembiayaan dari sumber dana lain apabila pekerjaan DAK telah selesai dilaksanakan pihak ketiga.

\subsection{Pertimbangan Prioritas Pembangunan Infrastruktur di Kabupaten Jembrana}

Untuk mewujudkan pembangunan yang tepat sasaran dan menyentuh kebutuhan masyarakat, diperlukan sinkronisasi perencanaan program pembangunan baik yang direncanakan oleh SKPD, Pemerintah Daerah maupun Pusat. Salah satu media untuk mewujudkan sinkronisasi perencanaan program pembangunan tersebut adalah Musyawarah Perencanaan Pembangunan ( Musrenbang) yang dilaksanakan secara berjenjang, dimulai dari tingkat desa/kelurahan, kecamatan, kabupaten, provinsi sampai dengan tingkat nasional. Musrenbang merupakan forum para pemangku kepentingan ( stakeholders ) untuk merencanakan program-program pembangunan sesuai dengan kebutuhan, kemampuan dan permasalahan yang dihadapi. Musrenbang yang diselenggarakan setiap tahun menghasilkan dokumen perencanaan pembangunan tahunan berupa Rencana Kerja Pemerintah (RKP) dan lima tahunan untuk Rencana Pembangunan Jangka Menegah ( RPJM ).

Konsep dasar pembangunan di Kabupaten Jembrana menekankan bahwa : pertama, pendidikan dan kesehatan merupakan kebutuhan dasar masyarakat yang menjadi tanggung jawab pemerintah sebagaimana tercantum dalam UUD 1945 pada tujuan negara, kedua : pendidikan, kesehatan dan daya beli merupakan komponen dasar dalam pembangunan kualitas hidup manusia yang disebut juga HDI ( Human Depelopment Indeks), ketiga : pelayanan umum masyarakat baik fisik maupun nonfisik merupakan bagian dari tugas pokok pemerintah sebagai regulator serta sebagai pengayom masyarakat. Pelayanan sosial semestinya jangan dijadikan sebagai seumber pendapatan bagi pemerintah melainkan lebih pada fungsi pengaturan dan perlindungan kepada masyarakat. Tema Pembangunan Nasional adalah : " Percepatan Pertumbuhan Ekonomi yang Berkeadilan Didukung Pemantapan Tata Kelola dan Sinergi Pusat Daerah". Untuk mewujudkan tema pembangunan nasional tersebut ditetapkan 19 prioritas Dinas Pekerjaan Umum antara lain sebagai berikut :

1. Prioritas 1 : Program Peningkatan Sarana dan Prasarana Aparatur

2. Prioritas 2: Program Pembangunan Jalan dan Jembatan

3. Prioritas 3: Program Pembangunan Saluran Drainase / Gorong-gorong

4. Prioritas 4: Program Rehabilitasi / Pemeliharaan Jalan dan Jembatan

5. Prioritas 5: Program Pembangunan Sistem Informasi / Data Base Jalan dan Jembatan

6. Prioritas 6 : Program Pengembangan dan Pengelolaan Jaringan Irigasi, Rawa dan Jaringan pengairan lainnya

7. Prioritas 7 : Program Pengembangan Kinerja Pengelolaan Air Minum dan Air Limbah

8. Prioritas 8: Program Pengendalian Banjir

9. Prioritas 9 : Program Pembangunan Wilayah Strategis dan Cepat Tumbuh

10. Prioritas 10 : Program Pembangunan Infrastruktur Perdesaan

11. Prioritas 11 : Program Pengembangan Perumahan

12. Prioritas 12 : Program Lingkungan Sehat Perumahan

13. Prioritas 13 : Program Pemberdayaan Komunitas Perumahan

14. Prioritas 14 : Program Perencanaan Tata Ruang

15. Prioritas 15 : Program Pemanfaatan Ruang

16. Prioritas 16 : Program Pengendalian Pemanfaatan Ruang

17. Prioritas 17: Program Pembinaan dan Pengawasan Bidang Pertambangan

18. Prioritas 18 : Program Pengawasan dan Penertiban Kegiatan Rakyat yang berpotensi Merusak Lingkungan

19. Prioritas 19 : Program Pembinaan dan Pengembangan Bidang Ketenagalistrikan

Keterkaitan tema dan prioritas pembangunan merupakan salah satu kunci keberhasilan pelaksanaan pembangunan. Dengan mengacu kepada tema dan prioritas pembangunan nasional dan provinsi, memperlihatkan keberhasilan pelaksanaan 
pembangunan yang telah dicapai pada tahun sebelumnya, mempertimbangkan isu, masalah serta tantangan yang masih dihadapi serta memperhatikan aspirasi para pemangku kepentingan ( stakeholders ) yang berkembang pada pelaksanaan Musrenbang maka ditetapkanlah tema dan prioritas pembangunan Kabupaten Jembrana yang sesuai dengan kondisi Kabupaten Jembrana ditetapkan tema yaitu : Dengan memperhatikan hal-hal tersebut diatas maka ditetapkan tema dan prioritas pembangunan Kabupaten Jembrana tahun 2015 adalah : "TERWUJUDNYA SARANA PRASARANA SERTA PELAYANAN PEKERJAAN UMUM KABUPATEN JEMBRANA YANG PRIMA, GUNA MENUNJANG KESEJAHTERAAN MASYARAKAT JEMBRANA"

Dalam mencapai tujuan dalam pembangunan infrastruktur di Kabupaten Jembrana maka pemerintah khususnya yang menangani di bidang sarana dan prasarana transportasi (infrastruktur) harus mempertimbangkan prioritas pembangunan yang nantinya pembangunan tersebut berjalan dengan baik dan sesuai dengan yang diharapkan. Dimana sasaran strategisnya yaitu meningkatkan infrastruktur jalan, jembatan dan bangunan yang berkualitas dan merata.

Pertimbangan prioritas pembangunan infrastruktur mengacu dari skala prioritas dengan memperhatikan jumlah pemanfaat dan memperhatikan akses ekonomi guna meningkatkan kesejahteraan masyarakat di Kabupaten Jembrana. Prioritas pembangunan juga harus disesuaikan dengan RPJM dan renstra.

\subsection{Penyaluran Anggaran Dalam Pembangunan Infrastruktur di Kabupaten Jembrana}

Tahapan dalam penyaluran anggaran untuk pembangunan infrastruktur di Kabupaten Jembrana yaitu sebagai berikut :

1. Musyawarah Perencanaan dan Pembangunan (Musrenbang)

Musrenbang Desa adalah forum masyawarah tahunan para pemangku kepetingan (stakeholder) desa untuk menyepakati rencana Kerja pembangunan Desa (RKP) tahun anggaran yang direncanakan. Murenbang Desa dilasanakan setiap bulan januari dengan mengacu pada RPJM desa. Setiap desa diamanatkan untuk menyusun dokumen rencana 5 tahunan yaitu RKP Desa.

2. Musyawarah Perencanaan Pembangunan (Musrenbang) kecamatan

Musrenbang kecamatan adalah forum musyawarah tahunan para pemangku kepetingan/stakeholders ditingkat kecamatan untuk mendapatkan masukan mengenai kegiatan prioritas pembangunan di wilayah kecamatan terkait yang didasarkan pada masukan dari hasil wilayah kecamatan terkait yang didasarkan pada masukan dari hasil Musrenbang kelurahan serta menyepakati rencana kegiatan lintas kelurahan dikecamatan yang bersangkutan. Masukan itu sekaligus sebagai dasar penyusunan Rencana Pembangunan Kecamatan yang akan diajukan kepada SKPD yang berwenang sebagai dasar penyusunan Rencana kerja Satuan Kerja Perangkat Daerah pada tahun berikutnya. Musrenbang kecamatan dilakukan setiap tahun pada bulan Febuari dengan luaran berupa Dokumen Rencana Pembangunan Kecamatan serta masukan untuk renja SKPD Kecamatan.

3. Musyawarah Perencanaan Pembangunan (Musrenbang) Kabupaten

Musyawarah Perencanaan Pembangunan (Musrenbang) dilakukan setiap tahun sebelum memsuki anggaran tahun berikutnya Musrenbang diawali dengan musrenbang pada tingkat desa dan selajutnya tingkat kecamatan pada prisipnya, usulan disusun dan disampaikan secara berjanjang /bertingkat mulai dari level RT/RW, Desa/Kelurahan yang telah terkumpul, akan digodok dan dimusyawarahkan, hasil musyawarah kecamatan ini dituangkan dalam satu dokumen berupa daftar usulan kegitan kecamatan akan diusulkan pada Musrenbang tingkat Kabupaten/Kota.

Pada tahap musrenbng Kabupaten/Kota, semua aspirasi yang masuk melalui musrenbang Kecamatan akan ditampung bersamaan dengan usulan kegiatan dari setiap Satuan Kerja Perangkat Daerah ( SKPD ). Forum ini merupakan pembahasan usulanusulan yang masuk, juga merupakan sarana dan fasilitas untuk melakukan koordinasi antara Kecamatan dengan SKPD yang bersangkutan khususnya untuk melakukan 
sinkronisasi terhadap usulan-usulan kegiatan setiap kecamatan. Usulan kecamatan akan dikelompokkan dan disesuaikan dengan jenis kegiatan SKPD yang berwenang untuk mengakomodir usulan tersebut. Pada tahap ini SKPD akan melakukan verifikasi terhadap usulan kecamatan sebelum dituangkan dalam daftar usulan kegiatan SKPD. Program/usulan kegiatan yang telah lolos pada tahap verifikasi akan dituangkan dalam Rencana Kerja Satuan Kerja Perangkat Daerah (Renja SKPD).

\section{Forum Satuan Kerja Perangkat Daerah}

Forum SKPD merupakan wadah bersama antar pelaku pembangunan untuk membahas prioritas kegiatan pembangunan hasil musrenbang kecamatan dengan SKPD atau gabungan SKPD sebagai upaya mengisi Rencana Kerja SKPD yang tata cara penyelenggarannya difasilitasi oleh SKPD terkait.

\section{Rencana Kerja (Renja)}

Rencana Kerja adalah salah satu instrument penting dalam perencanaan pembangunan daerah. Setelah tersusunnya Rencana Strategis (RENSTRA) di setiap SKPD Kabupaten Gunung Kidul diharapkan melalui RENJA maka penjabaran perencanaan tahunan dapat terdokumentasikan dan terealisasikan.

\section{RKA (Rencana Kerja Anggaran)}

Rencana kerja dan Anggaran yang disingkat RKA adalah dokumen perencanaan dan penganggaran yang berisi program dan kegiatan SKPD serta yang di perlukan untuk melaksanakanya

\section{DPA ( Doumen pelaksanaan Anggaran )}

Dokumen pelaksanaan anggaran yang disingkat DPA adalah dokumen yang memuat penapatan , belanja dan pembiayaan yang digunakan sebagai dasar pelaksaan anggaran oleh penggunaan anggara.

8. Dalam penganggaran pembangunan harus memperhatikan :

RPJMD ( Rencana Pembangunan Jangka Menengah Daerah ) merupakan dokumen perencanaan pembangunan daerah untuk jangka periode selama 5 tahunan yang berisi penjabaran dari visi, misi, dan program kepala daerah dengan berpedoman pada RPJP Daerah serta memperhatikan RPJM Nasional. Dalam RPJMD, menekankan tentang pentingnya menterjemahkan secara aktif tentang visi, misi dan agenda Kepala Daerah terpilih dalam tujuan, sasaran, strategi dan kebijakan pembangunan yang merespon kebutuhan dan aspirasi masyarakat serta kesepakatan tentang tolak ukur kinerja untuk mengukur keberhasilan pembangunan daerah dalam 5 tahun ke depan

- Renstra adalah suatu dokumen perencanaan yang berorientasi pada hasil yang ingin dicapai dalam kurun waktu 1-5 tahun sehubungan dengan tugas dan fungsi SKPD serta disuse dengan memperhitungkan perkembangan lingkungan strategis.

Adapun kegiatan pembangunan infrastruktur di Kabupaten Jembrana yaitu sebagai berikut :

1. Kegiatan rehabilitasi pemeliharan jalan

\begin{tabular}{|c|c|c|c|c|c|c|c|c|c|c|}
\hline \multirow{2}{*}{$\begin{array}{l}\text { Indikator } \\
\text { Kinerja } \\
\text { Utama }\end{array}$} & \multirow{2}{*}{ Satuan } & \multicolumn{2}{|c|}{ Tahun 2013} & \multirow[t]{2}{*}{$\%$} & \multicolumn{2}{|c|}{ Tahun 2014} & \multirow[t]{2}{*}{$\%$} & \multicolumn{2}{|c|}{ Tahun 2015} & \multirow[t]{2}{*}{$\%$} \\
\hline & & Target & Realisasi & & target & Realisasi & & target & Realisasi & \\
\hline $\begin{array}{l}\text { Persentase } \\
\text { jalan } \\
\text { dalam } \\
\text { kondisi } \\
\text { baik }(\%)\end{array}$ & $\%$ & $\begin{array}{c}64,00 \\
\mathrm{Km} .\end{array}$ & $\begin{array}{c}78,145 \\
\mathrm{Km} .\end{array}$ & 122,10 & $\begin{array}{c}66,00 \\
\mathrm{Km} .\end{array}$ & $\begin{array}{c}87,506 \\
\mathrm{Km} .\end{array}$ & 132,58 & $\begin{array}{l}46,80 \\
\mathrm{Km} .\end{array}$ & $\begin{array}{c}65,072 \\
\mathrm{Km} .\end{array}$ & 139,04 \\
\hline
\end{tabular}


Dari pencapaian target indikator kinerja utama sebagaimana tabel di atas menunjukkan bahwa ada peningkatan serapan anggaran terhadap pembangunan jalan sehingga kondisi jalan tetap dalam keadaan baik walaupun belum semua ruas jalan dapat direhabilitasi.

Jika dibandingkan dengan target akhir RPJMD pada tahun 2016 kinerja baru tercapai sebesar $139,04 \%$ sebagaimana dapat dilihat pada tabel di bawah ini :

Perbandingan IKU dengan target akhir RPJMD

\begin{tabular}{|c|c|c|c|c|c|c|c|}
\hline \multirow[t]{2}{*}{$\begin{array}{c}\text { Indikator Kinerja } \\
\text { Utama }\end{array}$} & \multirow[t]{2}{*}{ Satuan } & \multicolumn{2}{|c|}{ Tahun 2015} & \multirow[t]{2}{*}{$\%$} & \multicolumn{2}{|c|}{$\begin{array}{c}\text { Tahun } 2016 \\
\text { (akhir RPJMB) }\end{array}$} & \multirow[t]{2}{*}{$\%$} \\
\hline & & Target & Realisasi & & Target & $\begin{array}{l}\text { Realisasi } \\
\text { Th } 2015\end{array}$ & \\
\hline $\begin{array}{l}\text { Persentase jalan } \\
\text { dalam kondisi baik } \\
(\%)\end{array}$ & $\%$ & $\begin{array}{l}46,80 \\
\mathrm{Km} .\end{array}$ & $\begin{array}{c}65,072 \\
\mathrm{Km} .\end{array}$ & 139,04 & $\begin{array}{l}46,80 \\
\mathrm{Km} .\end{array}$ & $\begin{array}{l}65,072 \\
\mathrm{Km} .\end{array}$ & 139,04 \\
\hline
\end{tabular}

Pendukung Pencapaian IKU

\begin{tabular}{|l|l|c|c|c|}
\hline \multirow{2}{*}{ PROGRAM } & \multirow{2}{*}{ KEGIATAN } & \multicolumn{2}{|c|}{ ANGGARAN } & \multirow{2}{*}{ KET. } \\
\cline { 3 - 5 } & & PAGU & REALISASI & \\
\hline $\begin{array}{l}\text { Rehabilitasi/Pemeliharaan } \\
\text { Jalan dan jembatan }\end{array}$ & $\begin{array}{l}\text { Rehabilitasi } \\
\text { pemeliharaan } \\
\text { jalan }\end{array}$ & $\begin{array}{c}42.351 .209 .234 . \\
84\end{array}$ & 40.791 .218 .764 & \\
\hline
\end{tabular}

2. Kegiatan Pembangunan Jembatan

\begin{tabular}{|c|c|c|c|c|c|c|c|c|c|c|}
\hline \multirow{2}{*}{$\begin{array}{c}\text { Indikator Kinerja } \\
\text { Utama }\end{array}$} & \multirow[t]{2}{*}{ Satuan } & \multicolumn{2}{|c|}{ Tahun 2013} & \multirow[t]{2}{*}{$\%$} & \multicolumn{2}{|c|}{ Tahun 2014} & \multirow[t]{2}{*}{$\%$} & \multicolumn{2}{|c|}{ Tahun 2015} & \multirow[t]{2}{*}{$\%$} \\
\hline & & $\begin{array}{c}\text { Targe } \\
t\end{array}$ & $\underset{\mathrm{i}}{\text { Realisas }}$ & & target & $\underset{\mathrm{i}}{\text { Realisas }}$ & & $\begin{array}{c}\operatorname{targe} \\
t\end{array}$ & $\begin{array}{l}\text { Reali } \\
\text { sasi }\end{array}$ & \\
\hline $\begin{array}{l}\text { Persentase } \\
\text { jembatan dalam } \\
\text { kondisi baik (\%) }\end{array}$ & $\%$ & $3 \mathrm{Bh}$. & $5 \mathrm{Bh}$. & $\begin{array}{c}166,6 \\
7\end{array}$ & $3 \mathrm{Bh}$. & $4 \mathrm{Bh}$ & $\begin{array}{c}133,3 \\
3\end{array}$ & $2 \mathrm{Bh}$. & $\begin{array}{c}2 \\
\mathrm{Bh} .\end{array}$ & 100 \\
\hline
\end{tabular}

Dari pencapaian target Indikator Kinerja Utama sebagaimana tabel di atas menunjukkan bahwa Program Kegiatan Pembangunan jalan dan jembatan sudah terlaksana dengan baik sesuai dengan porsi anggaran yang ada dan dari tahun 2013 s/d 2015 sudah terbangun 15 buah jembatan panjang $1.752 \mathrm{M}$ yang dibangun dan tersebar di wilayah Kabupaten Jembrana.

Akses jalan menuju lokasi jembatan kondisinya sulit dilalui. Jika dibandingkan dengan target akhir RPJMD pada tahun 2016 kinerja baru tercapai 17,52 \% sebagaimana dapat dilihat pada tabel di bawah ini :

Perbandingan IKU dengan target akhir RPJMD

\begin{tabular}{|c|c|c|c|c|c|c|c|}
\hline \multirow[t]{2}{*}{$\begin{array}{c}\text { Indikator Kinerja } \\
\text { Utama }\end{array}$} & \multirow[t]{2}{*}{ Satuan } & \multicolumn{2}{|c|}{ Tahun 2015} & \multirow[t]{2}{*}{$\%$} & \multicolumn{2}{|c|}{$\begin{array}{c}\text { Tahun } 2016 \\
\text { (akhir RPJMB) }\end{array}$} & \multirow[t]{2}{*}{$\%$} \\
\hline & & Target & $\underset{\mathrm{i}}{\text { Realisas }}$ & & target & $\begin{array}{l}\text { Realisasi th } \\
2015\end{array}$ & \\
\hline $\begin{array}{l}\text { Persentase jembatan } \\
\text { dalam kondisi baik (\%) }\end{array}$ & $\%$ & $2 \mathrm{Bh}$. & $2 \mathrm{Bh}$. & 100 & $2 \mathrm{Bh}$. & $2 \mathrm{Bh}$. & 100 \\
\hline
\end{tabular}

Pendukung Pencapaian IKU 


\begin{tabular}{|l|l|c|c|c|}
\hline \multirow{2}{*}{ PROGRAM } & \multicolumn{1}{|c|}{ KEGIATAN } & \multicolumn{2}{|c|}{ ANGGARAN } & \multirow{2}{*}{ KET. } \\
\cline { 2 - 4 } $\begin{array}{l}\text { Pembangunan } \\
\text { Jalan dan } \\
\text { Jembaatan }\end{array}$ & $\begin{array}{l}\text { Pembangunan } \\
\text { Jembatan }\end{array}$ & 2.982 .783 .000 & 2.936 .905 .000 & \\
\hline
\end{tabular}

\begin{tabular}{|c|c|c|c|c|c|c|c|c|c|c|}
\hline \multirow{2}{*}{$\begin{array}{c}\text { Indikator } \\
\text { Kinerja Utama }\end{array}$} & \multirow{2}{*}{$\begin{array}{l}\text { Satu } \\
\text { an }\end{array}$} & \multicolumn{2}{|c|}{ Tahun 2013} & \multirow[t]{2}{*}{$\%$} & \multicolumn{2}{|c|}{ Tahun 2014} & \multirow[t]{2}{*}{$\%$} & \multicolumn{2}{|c|}{ Tahun 2015} & \multirow[t]{2}{*}{$\%$} \\
\hline & & Target & Realisasi & & target & Realisasi & & target & $\begin{array}{c}\text { Realis } \\
\text { asi }\end{array}$ & \\
\hline $\begin{array}{l}\text { Panjang } \\
\text { saluran irigasi } \\
\text { dan jaringan } \\
\text { pengairan } \\
\text { lainnya dalam } \\
\text { kondisi baik }\end{array}$ & $\mathrm{M}^{\prime}$ & $\begin{array}{c}4.219,0 \\
0 \mathrm{M}^{\prime}\end{array}$ & $\begin{array}{c}4.012,00 \\
M^{\prime}\end{array}$ & $\begin{array}{c}95,0 \\
9\end{array}$ & $\begin{array}{c}5.466,6 \\
6 \mathrm{M}^{\prime}\end{array}$ & $\begin{array}{c}6.257,37 \\
M^{\prime}\end{array}$ & $\begin{array}{c}114 \\
46\end{array}$ & $\begin{array}{l}5.466, \\
66 M^{\prime}\end{array}$ & $\begin{array}{l}5.020, \\
00 \mathrm{M}^{\prime}\end{array}$ & $\begin{array}{c}91,8 \\
3\end{array}$ \\
\hline
\end{tabular}

3. Kegiatan Rehabilitas atau pemeliharan Jaringan Irigasi

Dari pencapaian target Indikator KInerja Utama sebagaimana tabel di atas, menunjukkan bahwa, program Pengembangan dan pengelolaan jaringan irigasi,rawa dan jaringan pengairan lainnya berjalan sesuai dengan rencana dari tahun $2013 \mathrm{~s} / \mathrm{d}$ 2015. Tidak ada kendala yang prinsip dalam melaksanakan program kegiatan ini.

Jika dibandingkan dengan target akhir RPJMD pada Tahun 2016 kinerja baru tercapai sebesar 91,83. \%, sebagaimana dapat dilihat pada tabel dibawah ini :

Perbandingan IKU dengan Target Akhir RPJMD

\begin{tabular}{|c|c|c|c|c|c|c|c|}
\hline \multirow[t]{2}{*}{$\begin{array}{c}\text { Indikator Kinerja } \\
\text { Utama }\end{array}$} & \multirow[t]{2}{*}{ Satuan } & \multicolumn{2}{|c|}{ Tahun 2015} & \multirow[t]{2}{*}{$\%$} & \multicolumn{2}{|c|}{$\begin{array}{c}\text { Tahun } 2016 \\
\text { (akhir RPJMB) }\end{array}$} & \multirow[t]{2}{*}{$\%$} \\
\hline & & target & Realisasi & & target & $\begin{array}{c}\text { RealisasiTh } \\
2015\end{array}$ & \\
\hline $\begin{array}{l}\text { Panjang saluran } \\
\text { irigasi dan } \\
\text { jaringan } \\
\text { pengairan lainnya } \\
\text { dalam kondisi } \\
\text { baik }\end{array}$ & $\mathrm{M}^{\prime}$ & $\begin{array}{c}5.467 \\
M^{\prime}\end{array}$ & $5.020 \mathrm{M}^{\prime}$ & 91,83 & $\begin{array}{c}5.467 \\
M^{\prime}\end{array}$ & $5.020 \mathrm{M}^{\prime}$ & 91,83 \\
\hline
\end{tabular}

PENDUKUNG PENCAPAIAN IKU

\begin{tabular}{|l|c|c|c|c|}
\hline \multicolumn{1}{|c|}{ PROGRAM } & KEGIATAN & \multicolumn{2}{|c|}{ ANGGARAN } & \multirow{2}{*}{ KET. } \\
\cline { 3 - 4 } & & PAGU & REALISASI & \\
\hline $\begin{array}{l}\text { Pengembangan dan } \\
\text { pengelolaan jaringan } \\
\text { irigasi, rawa dan } \\
\text { jaringan pengairan } \\
\text { lainnya }\end{array}$ & $\begin{array}{l}\text { Rehabilitasi } \\
\text { /pemeliharaan } \\
\text { jaringan irigasi }\end{array}$ & 7.530 .932 .820 & 7.307 .549 .000 & \\
& & & & \\
\end{tabular}

4. Kegiatan penyusunan Rancangan Peraturan Daerah ( RANPERDA ) RDTR dan peraturan Zonasi

Jumlah rumah ber-IMB tahun ini - Jumlah rumah ber-IMB tahun sebelumnya $\times 100 \%$ 
Jurnal IImiah Akuntansi danHumanika, Vol. 8 No. 2, Agustus 2018 ISSN: 2599-2651

\begin{tabular}{|c|c|c|c|c|c|c|c|c|c|c|}
\hline \multirow{2}{*}{$\begin{array}{l}\text { Indikator } \\
\text { Kinerja } \\
\text { Utama }\end{array}$} & \multirow[t]{2}{*}{ Satuan } & \multicolumn{2}{|c|}{ Tahun 2013} & \multirow[t]{2}{*}{$\%$} & \multicolumn{2}{|c|}{ Tahun 2014} & \multirow[t]{2}{*}{$\%$} & \multicolumn{2}{|c|}{ Tahun 2015} & \multirow[t]{2}{*}{$\%$} \\
\hline & & Target & Realisasi & & target & Realisasi & & target & Realisasi & \\
\hline $\begin{array}{l}\% \\
\text { peningkatan } \\
\text { Jlh rumah yg } \\
\text { memiliki IMB }\end{array}$ & $\%$ & 997 & 2.223 & 12.26 & 1000 & 2.583 & 3.60 & 300 & 3.085 & 5.02 \\
\hline
\end{tabular}

Dari pencapaian target Indikator KInerja Utama sebagaimana tabel di atas, menunjukkan bahwa, ada peningkatan realisasi. Jika dibandingkan dengan target akhir RPJMD pada Tahun 2016 kinerja baru tercapai sebesar $30 \%$, sebagaimana dapat dilihat pada tabel dibawah ini :

Perbandingan IKU dengan Target Akhir RPJMD

\begin{tabular}{|c|c|c|c|c|c|c|c|}
\hline \multirow{2}{*}{$\begin{array}{c}\text { Indikator Kinerja } \\
\text { Utama }\end{array}$} & \multirow{2}{*}{ Satuan } & \multicolumn{2}{|c|}{ Tahun 2015 } & & \multicolumn{2}{|c|}{$\begin{array}{c}\text { Tahun 2016 (akhir } \\
\text { RPJMB) }\end{array}$} & \multirow{2}{*}{$\%$} \\
\cline { 3 - 4 } \cline { 5 - 6 } & & Target & Realisasi & & target & $\begin{array}{c}\text { RealisasiTh } \\
2015\end{array}$ & \\
\hline $\begin{array}{c}\text { \% peningkatan Jlh } \\
\text { rumah yg memiliki } \\
\text { IMB }\end{array}$ & Unit & 3.085 & 300 & 30,85 & 300 & 3.085 & 30 \\
\hline
\end{tabular}

PENDUKUNG PENCAPAIAN IKU

\begin{tabular}{|c|c|c|c|c|}
\hline \multirow{2}{*}{ PROGRAM } & \multirow{2}{*}{ KEGIATAN } & \multicolumn{2}{|c|}{ ANGGARAN } & \multirow{2}{*}{ KET. } \\
\hline & & PAGU & REALISASI & \\
\hline $\begin{array}{l}\text { Program } \\
\text { Pengembangan } \\
\text { Perumahan }\end{array}$ & $\begin{array}{l}\text { Penyusunan } \\
\text { Rancangan } \\
\text { Peraturan Daerah } \\
\text { (RANPERDA)RDTR } \\
\text { dan peraturan } \\
\text { Zonasi }\end{array}$ & 198.126 .200 & 165.848 .606 & \\
\hline
\end{tabular}

5. Kegiatan Penyusunan Rencana Teknis Tata Ruang Kawasan Jumlah Perda RTRW dan turunnya

\begin{tabular}{|c|c|c|c|c|c|c|c|c|c|c|}
\hline \multirow{2}{*}{$\begin{array}{l}\text { Indikator } \\
\text { Kinerja } \\
\text { Utama }\end{array}$} & \multirow[t]{2}{*}{ Satuan } & \multicolumn{2}{|c|}{ Tahun 2013} & \multirow[t]{2}{*}{$\%$} & \multicolumn{2}{|c|}{ Tahun 2014} & \multirow[t]{2}{*}{$\%$} & \multicolumn{2}{|c|}{ Tahun 2015} & \multirow[t]{2}{*}{$\%$} \\
\hline & & Target & Realisasi & & target & Realisasi & & target & Realisasi & \\
\hline $\begin{array}{l}\text { Keberadaan } \\
\text { Perda } \\
\text { RTRW }\end{array}$ & $\%$ & 1 & 1 & 100 & 1 & 1 & 100 & 1 & 1 & 100 \\
\hline
\end{tabular}

Turunan Perda RTRW yang telah disusun masih berupa materi teknis belum berupa Perda. Dari pencapaian target Indikator KInerja Utama sebagaimana tabel di atas, menunjukkan bahwa, turunan dari Perda TRRW baru 47,37 \% yang dapat dibuatkan Rencana Rinciannya. Jika dibandingkan dengan target akhir RPJMD pada Tahun 2016 kinerja baru tercapai sebesar $100 \%$, sebagaimana dapat dilihat pada tabel dibawah ini :

Perbandingan IKU dengan Target Akhir RPJMD

\begin{tabular}{|c|c|c|c|c|c|c|c|}
\hline \multirow{2}{*}{$\begin{array}{c}\text { Indikator } \\
\text { Kinerja Utama }\end{array}$} & \multirow{2}{*}{ Satuan } & \multicolumn{2}{|c|}{ Tahun 2015} & \multirow[t]{2}{*}{$\%$} & \multicolumn{2}{|c|}{$\begin{array}{c}\text { Tahun } 2016 \quad \text { (akhir } \\
\text { RPJMB) }\end{array}$} & \multirow[t]{2}{*}{$\%$} \\
\hline & & Target & Realisasi & & target & RealisasiTh & \\
\hline
\end{tabular}


Jurnal Ilmiah Akuntansi danHumanika, Vol. 8 No. 2, Agustus 2018

ISSN: 2599-2651

\begin{tabular}{|c|c|c|c|c|c|c|c|}
\hline & & & & & & 2015 & \\
\hline $\begin{array}{c}\text { Keberadaan } \\
\text { Perda RTRW }\end{array}$ & $\%$ & 1 & 1 & 100 & 1 & 1 & 100 \\
\hline
\end{tabular}

PENDUKUNG PENCAPAIAN IKU

\begin{tabular}{|l|l|c|c|c|}
\hline \multirow{2}{*}{ PROGRAM } & \multicolumn{1}{|c|}{ KEGIATAN } & \multicolumn{2}{|c|}{ ANGGARAN } & \multirow{2}{*}{ KET. } \\
\cline { 3 - 4 } & PAGU & REALISASI & \\
\hline $\begin{array}{l}\text { Program } \\
\text { Perencanaan } \\
\text { Tata Ruang }\end{array}$ & $\begin{array}{l}\text { Penyusunan } \\
\text { Rencana Teknis } \\
\text { Tata Ruang } \\
\text { Kawasan }\end{array}$ & 359.907 .200 & 281.275 .500 & \\
\hline
\end{tabular}

6. Kegiatan Pembangunan sarana dan prasarana air minum Jumlah RT pakai air bersih X $100 \%$ Jumlah RT

\begin{tabular}{|c|c|c|c|c|c|c|c|c|c|c|}
\hline \multirow[t]{2}{*}{ IndikatorKinerjaUtama } & \multirow{2}{*}{$\begin{array}{l}\text { Sat } \\
\text { Uan }\end{array}$} & \multicolumn{2}{|c|}{ Tahun 2013} & \multirow[t]{2}{*}{$\%$} & \multicolumn{2}{|c|}{ Tahun 2014} & \multirow[t]{2}{*}{$\%$} & \multicolumn{2}{|c|}{ Tahun 2015} & \multirow[t]{2}{*}{$\%$} \\
\hline & & Target & Realisasi & & target & Realisasi & & target & Realisasi & \\
\hline $\begin{array}{l}\text { Persentase Rumah } \\
\text { angga (RT) yang } \\
\text { lenggunakan Air Bersih }\end{array}$ & $\%$ & 25.000 & 33,35 & 13,34 & 26.000 & 34.68 & 13,33 & 23.000 & 30.68 & $\begin{array}{l}13 \\
33\end{array}$ \\
\hline
\end{tabular}

Dari pencapaian target Indikator KInerja Utama sebagaimana tabel di atas, menunjukkan bahwa, prosentase rumah tangga (RT) yang menggunakan air bersih mencapai setengah dari jumlah rumah tangga di Kabupaten Jembrana.

Jika dibandingkan dengan target akhir RPJMD pada Tahun 2016 kinerja baru tercapai sebesar 77,76 . \%, sebagaimana dapat dilihat pada tabel dibawah ini :

Perbandingan IKU dengan Target Akhir RPJMD

\begin{tabular}{|c|c|c|c|c|c|c|c|}
\hline \multirow[t]{2}{*}{ katorKinerjaUtama } & \multirow[t]{2}{*}{ Satuan } & \multicolumn{2}{|c|}{ Tahun 2015} & \multirow[t]{2}{*}{$\%$} & \multicolumn{2}{|c|}{$\begin{array}{c}\text { Tahun } 2016 \quad \text { (akhir } \\
\text { RPJMB) }\end{array}$} & \multirow[t]{2}{*}{$\%$} \\
\hline & & target & Realisasi & & target & $\begin{array}{l}\text { RealisasiTh } \\
2015\end{array}$ & \\
\hline $\begin{array}{l}\text { Persentase } \\
\text { Rumah Tangga } \\
\text { (RT) yang } \\
\text { Menggunakan Air } \\
\text { Bersih }\end{array}$ & $\%$ & 5 & 2.153 .418 .740 & 67.73 & 5 & 2.500 .000 .000 & 77.76 \\
\hline
\end{tabular}

PENDUKUNG PENCAPAIAN IKU

\begin{tabular}{|c|c|c|c|c|}
\hline \multirow{2}{*}{ PROGRAM } & \multirow{2}{*}{ KEGIATAN } & \multicolumn{2}{|c|}{ ANGGARAN } & \multirow{2}{*}{ KET } \\
\hline & & PAGU & REALISASI & \\
\hline $\begin{array}{l}\text { Pengembangan } \\
\text { Kinerja } \\
\text { Pengelolaan air } \\
\text { minum dan air } \\
\text { limbah }\end{array}$ & $\begin{array}{l}\text { Pembangunan } \\
\text { sarana dan } \\
\text { prasarana air } \\
\text { minum }\end{array}$ & 3.179258 .950 & 2.153 .418 .740 & \\
\hline
\end{tabular}

\section{Simpulan dan Saran}

Perkembangan pembangunan infrastruktur di kabupaten Jembrana dapat dilihat dari pembangunan transportasinya, transportasi di bagi kembali menjadi dua yaitu Jalan menurut statusnya ada tiga jenis jalan di kabupaten Jembrana yaitu jalan Nasional $(71,320 \mathrm{~km})$, jalan 
Provinsi $(30,870 \mathrm{~km})$ dan jalan Kabupaten $(941,023 \mathrm{~km})$. Panjang jalan di kabupaten Jembrana tahun 2015 yaitu 941,023 km dngan ruas jalan sebanyak 653 (aspal 915,522 km dan krikil 25,501 km. Jembatan nasional dari tahun 2013 tercatat berjumlah 38 jembatan hinggatahun 2015 dengan menggunakan bahan kontruksi beton. Jembatan provinsi dari tahun 2013 sampai tahun 2015 tercatat sejumlah 3 dengan menggunkan bahan kontruksi beton. Jembatan kabupaten dari tahun 2013 sampai dengan 2015 tercatat sejumlah 96 dengan bahan kontruksi beton dan baja.

Rencana Strategik yang memuat rencana dalam kurun waktu lima tahun telah disusun sesuai dengan tahapannya, faktor-faktor penghambat dan faktor-faktor pendorong dan juga memperhitungkan tantangan dan peluang untuk pengembangan dan peningkatan mutu pelayanan. Untuk mencapai tujuan dan sasaran sesuai dengan Visi, Misi yang ditetapkan ditempuh melalui kebijakan program dan kegiatan, yang dihimpun berdasarkan Musrenbangdes, Musrenbangcam dan Musrenbangkab. Program yang dihasilkan melalui Musrenbang tersebut dipadukan dan disingkrunkan dengan rencana program yang ditetapkan oleh pemerintah pusat, provinsi dan kabupaten yang dituangkan dalam Rensta. Program dari kegiatan tahunan yang telah ditetapkan melalui Dokumen Pelaksanaan Anggaran (DPA) untuk mencapai hasil yang maksimal dilaksanakan berdasarkan prinsip efisien, efektif, transparan dan akuntabel. Keberhasilan dari program dan kegiatan sangat diperlukan partisipasi semua pihak baik pemerintah, swasta, masyarakat dan juga dari DPRD. Dan pada akhir tahun wajib dilakukan evaluasi pelaksanaan kegiatan untuk mengukur tingkat keberhasilan, dan mengetahui penyebab masalah yang menghambat pencapaian. Tujuan dan sasaran, dimana hasil dari evaluasi tahunan tersebut dituangkan kedalam Laporan Akuntabilitas Kinerja Instansi Pemerintah (LAKIP). Adapun Renstra disusun sebagai pedoman untuk melaksanakan Program dan Kegiatan sampai lima tahun mendatang.

Dalam hal pembangunan infrastruktur di kabupaten Jembrana tindakan pemerintrah dalam hal ini adalah dengan melakukan perencanan kinerja. Perencanaan kinerja Dinas pekerjaan Umum Kabupaten Jembrana merupakan proses penyusunan rencana kinerja sebagai penjabaran dari sasaran dan program yang telah ditetapkan dalam rencana strategik, yang akan dilakasanakan oleh Dinas Pekerjaan Umum melalui berbagai kegiatan tahunan. Perencanaan tahunan merupakan proses penetapan kegiatan tahunan dan indikator kinerja berdaarkan program, kebijakan dan sasaran yang telah ditetapkan dalam rencana strategik.

Pertimbangan prioritas pembangunan infrastruktur mengacu dari skala prioritas dengan memperhatikan jumlah pemanfaat dan memperhatikan akses ekonomi guna meningkatkan kesejahteraan masyarakat di Kabupaten Jembrana. Prioritas pembangunan juga harus disesuaikan dengan RPJM dan renstra. Dalam penganggaran pembangunan harus memperhatikan RPJMD ( Rencana Pembangunan Jangka Menengah Daerah) dan Renstra

Dari kesimpulan di atas, maka saran yang dapat diberikan yaitu dalam pembangunan infrastruktur di Kabupaten Jembrana agar kedepannya dapat mengatur penyaluran anggaran untuk pembangunan infrastruktur agar masalah dalam pengalokasian dana ataupun penganggaran dana menjadi lebih baik, sehingga pembangunan infrastruktur mampu berjalan secara optimal dan terealisasi dengan baik.

\section{DAFTAR PUSTAKA}

http://info-anggaran.com/ensiklopedia/musyawarah-perencanaan-dan-pembanguna-desa/. http://info-anggaran.com/ensiklopedia/musrenbang-kecamatan/. http://upk-pnpmsurade.org/pto-pnpm/3-alur-kegiatan-pnpm-mp/31-forum-satuan-kerjaperangkat-daerah-skpd.html. http://harfihambani.blogspot.co.id/2015/07/apa-itu-rpimd-renstra.html. LAKIP PU Kab. Jembrana RENSTRA PU 2015 